\title{
Effectiveness of Barrier Creams against Irritant Contact Dermatitis
}

\author{
Christian Mostosi $^{\mathrm{a}} \quad$ Thierry Simonart $^{\mathrm{b}}$ \\ ${ }^{\mathrm{a} C E S I}$ Prévention et Protection asbl., Charleroi, and ${ }^{\mathrm{b}}$ Private practice, Brussels, Belgium
}

\section{Key Words}

Barrier cream · Skin protection · Workplace · Irritant · Review

\begin{abstract}
Introduction: Skin tissue is frequently exposed to various irritant substances in the workplace, particularly in wet work, which can lead to the development of occupational contact dermatitis. 'Barrier' creams (BCs) are well known, and their applications are still the subject of many studies and controversies. Methods: We searched all controlled trials investigating $B C s$ against cutaneous irritants in humans published between 1956 and December 2014 from MEDLINE, PubMed, reference lists and existing reviews. Results: Thirty-nine studies about the effects of BCs against skin irritants in humans were selected. Among these, 27 trials in healthy volunteers were found to show many differences with regard to $\mathrm{BCs}$ and irritants used, their quantities, test locations, procedures and assessment methods. Finally, 14 patch test trials assessed by clinical scoring and evaporimetry emerged. Although the findings were generally positive, only few findings could be cross-checked from all the data, and vehicles seem to be as effective as BCs. Conclusion: Although this review highlights the poor quality and the lack of standard-
\end{abstract}

ization of most studies, BCs seem to have protective effects against irritants. Further well-designed, adequately powered randomized controlled trials with clinical and biophysical assessments are required.

(c) 2016 S. Karger AG, Basel

\section{Introduction}

Occupational contact dermatitis (OCD) represents $90 \%$ of all occupational skin diseases, of which the annual incidence is 9.1-31.7 per 100,000 workers [1]. Change of job occurs in $29-72 \%$ of the cases [2]. The European OCD prevalence, during a defined 1-year period, is estimated to be between 6.7 and $10.6 \%$ [3].

Acute or chronic exposure to irritants can lead to irritant contact dermatitis, representing $80 \%$ of all OCDs [3]. Irritant contact dermatitis is caused by a non-immunological reaction which may be immediate or cumulative over time. It is found mainly in 'wet-work' occupations such as household-cleaning workers, dish washers, people who work in the food industry such as bakers, health care workers, hairdressers or metal workers $[4,5]$. Some extraprofessional activities like gardening, do-

\section{KARGER}

E-Mail karger@karger.com www.karger.com/drm
(C) 2016 S. Karger AG, Basel

$1018-8665 / 16 / 2323-0353 \$ 39.50 / 0$
Christian Mostosi

Avenue Jean-Sibélius 16/74

BE-1070 Brussels (Belgium)

E-Mail christian.mostosi@ cesi.be 
mestic work or do-it-yourself could be a confounding factor.

Damaged, dry and rough skin increases the penetration of substances in the stratum corneum, acting as a reservoir for the substances which have penetrated [6].

Among skin creams, two types of products for hand protection may be found: barrier protection creams or 'barrier' creams (BCs) and barrier repair creams [7]. BCs are used to prevent the irritant effect caused by occupational exposure and are recommended for application before and during work. Some authors call them prework creams [8-10]. They have also been called invisible gloves' but the term 'skin protective creams' is more appropriate [10]. The objective of the BCs is to inhibit or delay cutaneous penetration of substances which could have deleterious effects at the time of skin contact or induce systemic effects due to percutaneous absorption [11]. BCs are therefore used to reduce the irritant effect of substances, preventing irritant contact dermatitis. Barrier repair creams, also called 'regeneration creams', 'conditioning creams', 'emollients' or 'moisturizers' [10], are intended to enhance hydration by way of the hygroscopic action of humectants, such as amino acids, urea, glycerine, lactic acid (LA) or pyrrolidone carboxylic acid [12], and to restore the skin's natural barrier. They are especially recommended for use after work [13].

Despite controversies, the Cochrane database [14] showed that BCs and moisturizers may have a protective effect in some occupations including metal, printing and dye work, however without statistical significance reached from their 4 selected studies. Enlarging the focus on controlled trials investigating BCs against cutaneous irritants, we performed a systematic analysis in order to see if complementary data could be found on their effectiveness.

\section{Materials and Methods}

For further details, see the supplementary materials (for all online suppl. material, see www.karger.com/doi/10.1159/000444219) (fig. 1; tables 1-4).

\section{Results}

We identified 39 controlled trials (table 1) investigating the effect of BCs against skin irritants in a total of 929 volunteers (172 men, 279 women and 481 unspecified subjects) with healthy skin $(\mathrm{n}=28)$, hand dermatitis $(\mathrm{n}=$

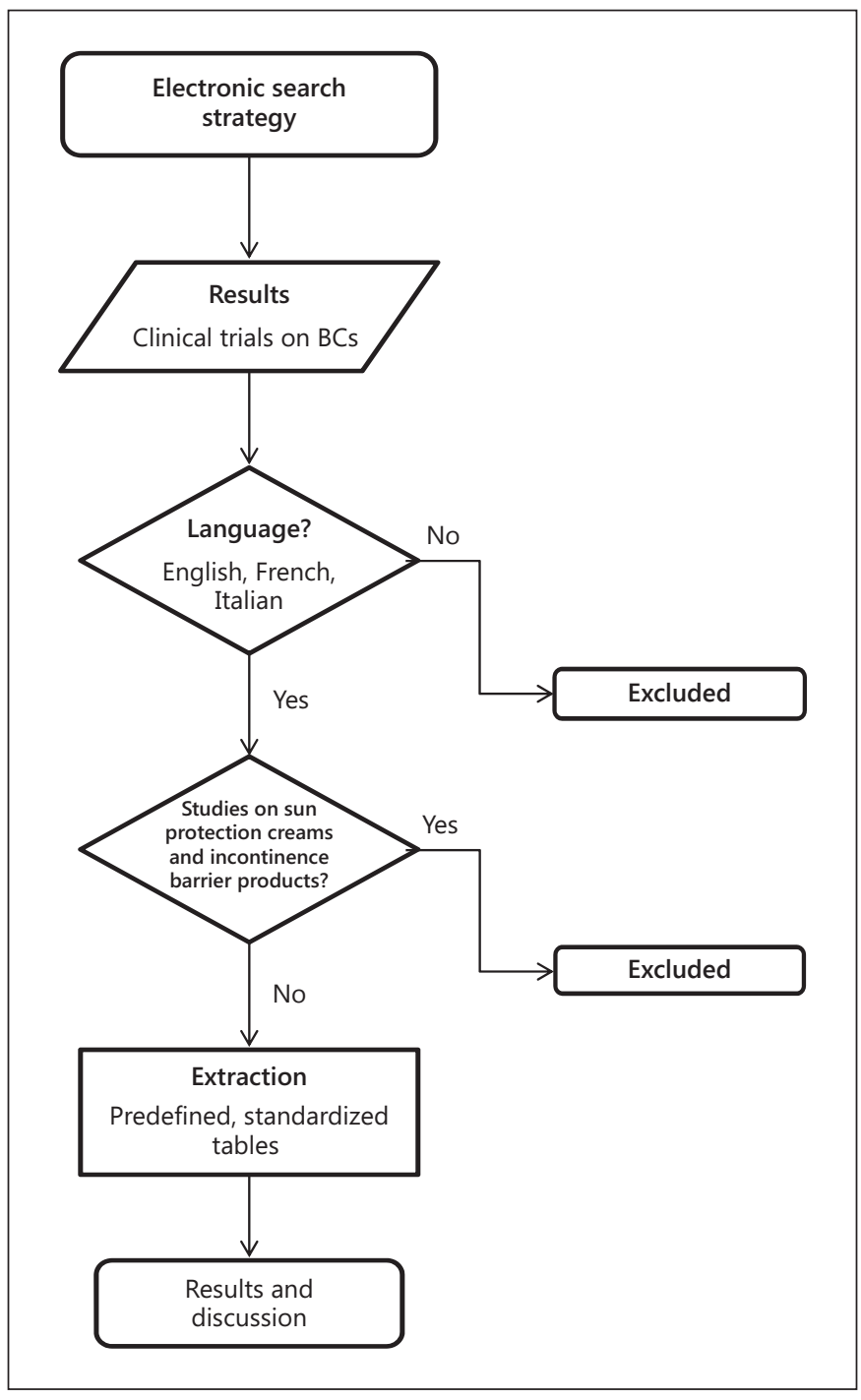

Fig. 1. Flowchart.

$1)$, skin sensitized to a specific allergen $(n=4)$ and 1 study on latex glove allergens $[6,15-52]$. From these 39 papers, studies on excised skin $[18,24,40,41,43,46]$ have been discarded, and only trials on subjects with healthy and non-sensitized skin were retained, reducing the list to 27 papers detailed in table 1. Untreated skin was used in each trial as a control. The skin localizations in subjects were the forearms $(n=15)$, back $(n=8)$, hands $(n=3)$, forearms and back $(\mathrm{n}=1)$. Stokoderm ${ }^{\circledR}(\mathrm{n}=3)$, Taktosan ${ }^{\circledR}$ $(n=3), \operatorname{Kerodex} 71^{\circledR}(n=2)$ and Arretil ${ }^{\circledR}(n=2)$ are the 4 most frequently investigated creams. Several articles mention only the composition of the creams studied with no commercial name. The amounts of $\mathrm{BC}$ used range 


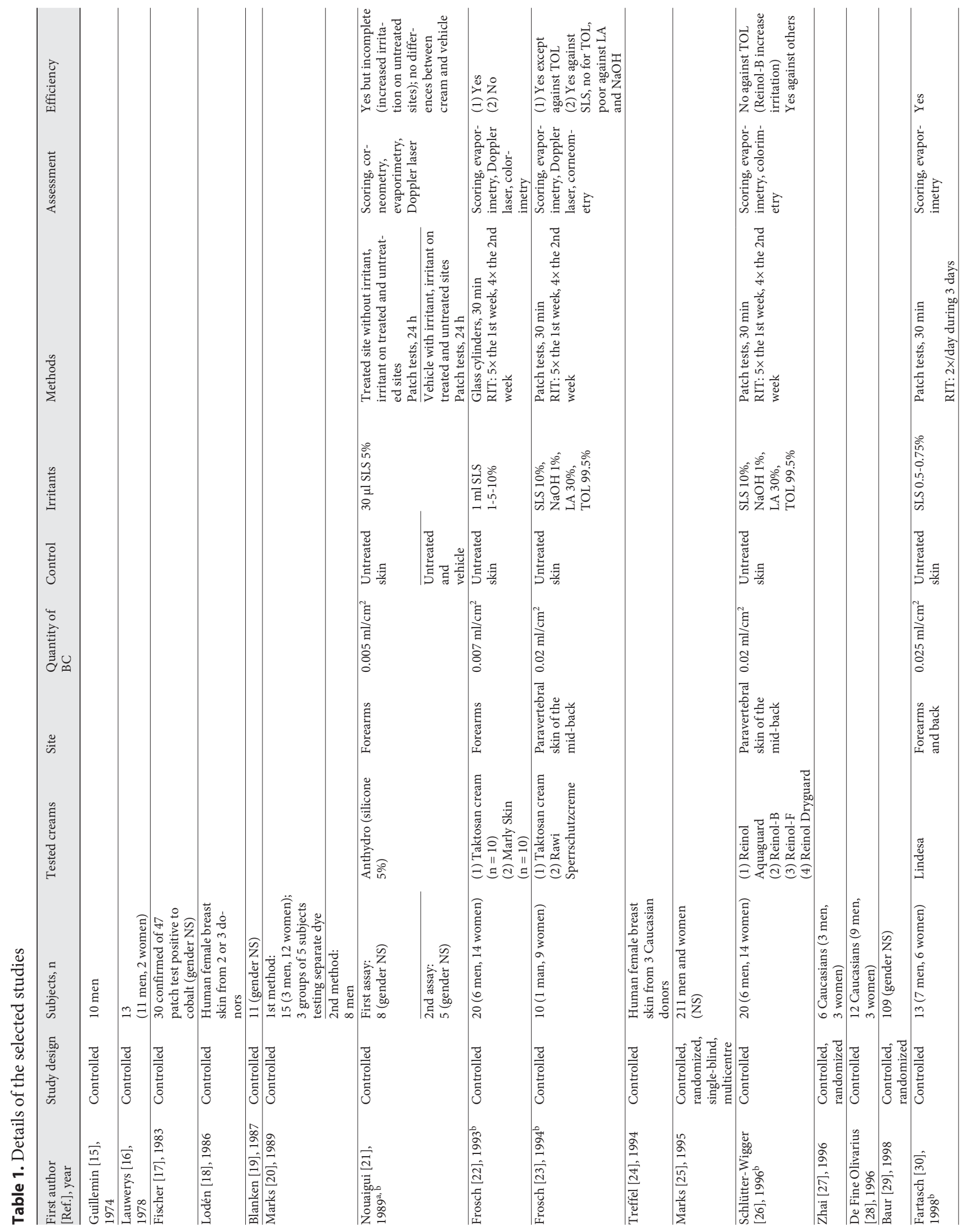




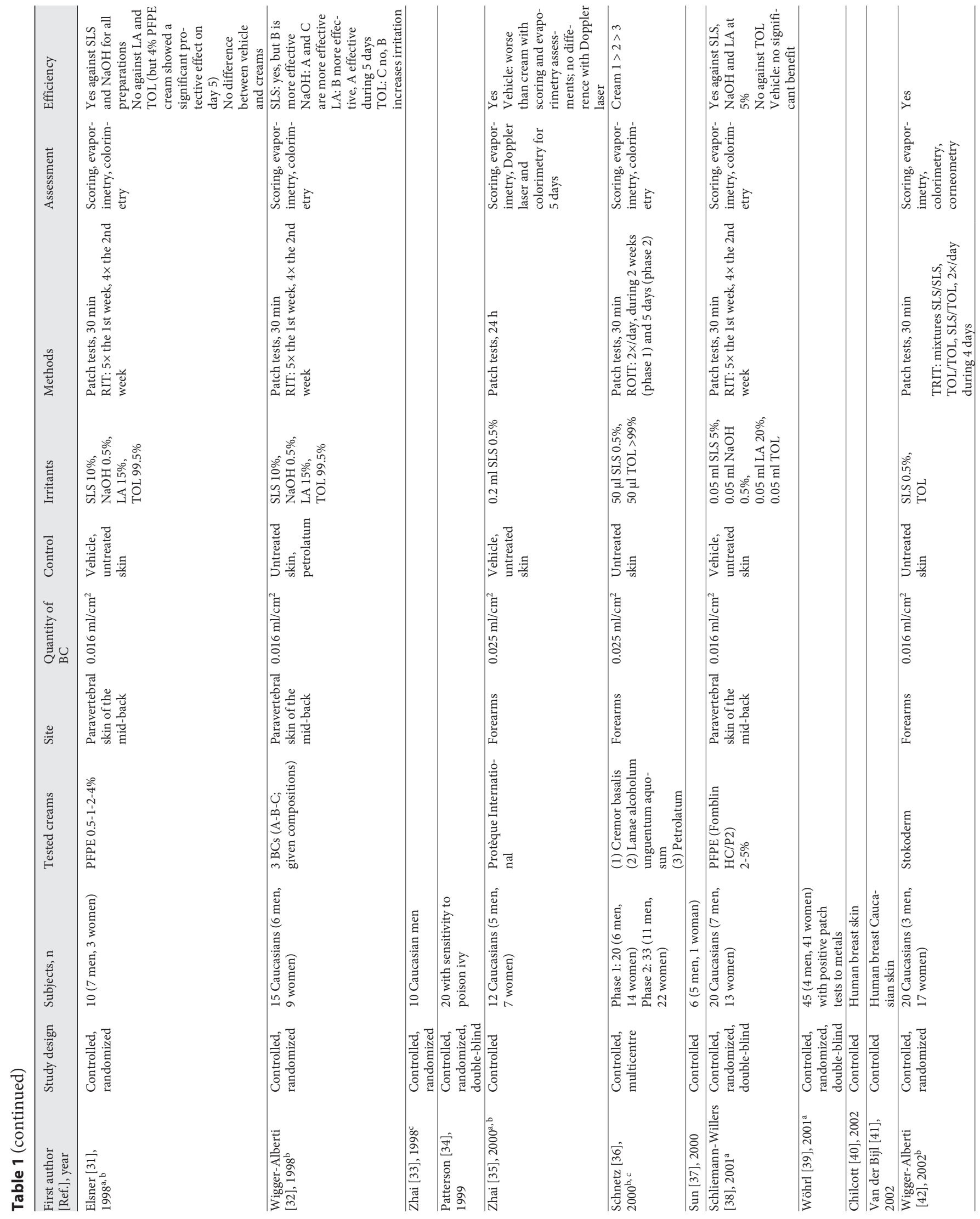




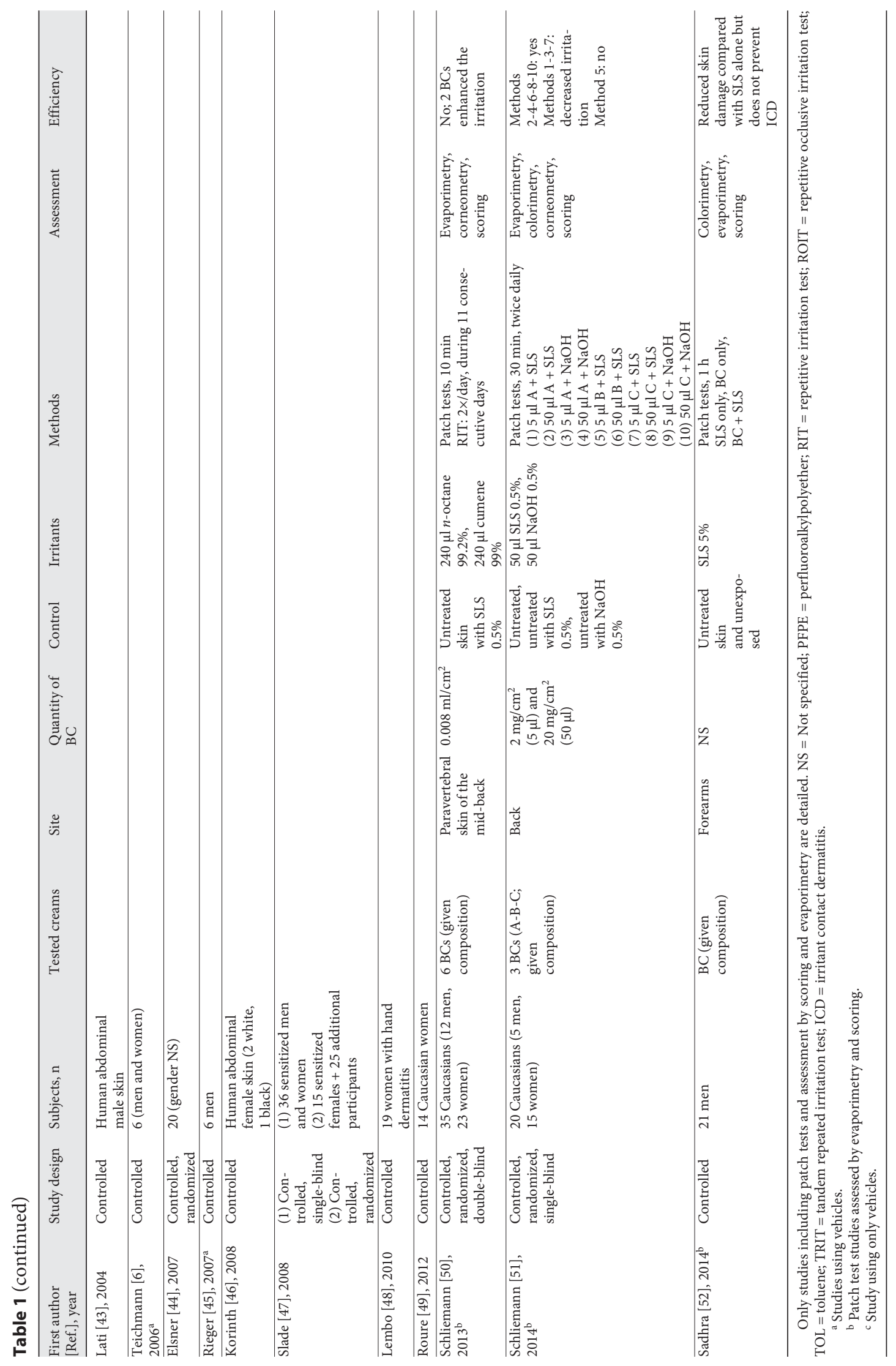


Table 2. Protective effect of the 4 most tested BCs

\begin{tabular}{|c|c|c|c|c|c|c|c|c|}
\hline Stokoderm & - & - & Yes & Yes & - & - & Yes & - \\
\hline Taktosan & - & - & - & - & Yes & Yes & Yes & - \\
\hline Kerodex & Yes & Yes & - & - & - & - & - & - \\
\hline
\end{tabular}

Reproducible results are in italics.

Table 3. Number of named BCs showing a protective or no protective effect on the 4 most used irritants

\begin{tabular}{lll}
\hline \multirow{2}{*}{ Irritants } & \multicolumn{2}{l}{ Number of BCs reported } \\
\cline { 2 - 3 } & protective effect & no protective effect \\
\hline SLS & 13 & 1 \\
Toluene & 1 & 8 \\
NaOH & 8 & - \\
LA & 7 & 1 \\
\hline
\end{tabular}

from 0.25 to $20 \mathrm{mg} / \mathrm{cm}^{2}$ and from 2 to $25 \mu \mathrm{l} / \mathrm{cm}^{2}$. The most used irritants are sodium lauryl sulphate (SLS, hydrophilic model, $\mathrm{n}=16$ ) and toluene (lipophilic model, $\mathrm{n}=9)$. Sodium hydroxide $(\mathrm{NaOH}, \mathrm{n}=7)$ and $\mathrm{LA}(\mathrm{n}=5)$ are other common irritants tested. Their concentrations range, according to the authors, from 0.5 to $10 \%$ for SLS, from 0.5 to $4 \%$ for $\mathrm{NaOH}$ and from 15 to $30 \%$ for LA, whereas toluene was used pure ( $>99 \%)$. The quantity of irritants used is often not specified. However, a range from 0.03 to $1 \mathrm{ml}$ of SLS was applied (specified in 6 trials) and from 0.05 to $0.1 \mathrm{ml}$ for $\mathrm{NaOH}$ (specified in 3 studies). The contact time of irritants ranges from $5 \mathrm{~s}$ to $24 \mathrm{~h}$ but the most frequent contact time is $30 \mathrm{~min}(\mathrm{n}=11)$ and $24 \mathrm{~h}(\mathrm{n}=4)$. Repetitive irritation tests, including repetitive occlusive irritation tests and tandem repetitive irritation tests, were performed in 11 studies [22, 23, 26, 30-32, $36,38,42,44,50]$. The assessment methods often consist of clinical scoring of irritation after cutaneous patch tests $(\mathrm{n}=17)$ and bioengineering methods which are habitually evaporimetry $(n=17)$, colorimetry $(n=12)$, corneometry $(n=7)$, flow velocimetry by Doppler laser $(n=6)$, spectrometry $(n=3)$ or other more infrequently used methods. Two studies showed an increased penetration of the irritant $[27,45]$, and the irritation increased in 3 trials $[26,32,50]$. Table 2 displays the protective effects of the 4 most used BCs. It shows that Stokoderm was effective against SLS $0.5 \%$ and toluene in 2 studies $[42,44]$. The efficiency of this same BC against Oil red $\mathrm{O}$ (a staining dye) was confirmed by only 1 study [27]. Taktosan was found to be effective against SLS $10 \%$ in 2 different studies from the same author $[22,23]$. Fourteen patch test studies assessed by scoring and evaporimetry (table 1) were selected to better compare the results in tables 3 and 4. In table 3, which reports the presence or absence of efficiency of the named BCs on the 4 most used irritants, we can see that BCs seem to have protective effects against SLS, $\mathrm{NaOH}$ and LA, but not against toluene. Four studies $[21,31,35,38]$ compared BCs with vehicles. The results displayed in table 4 show no difference $(n=3)$ [21, 31,38] and a worse effect for scoring and evaporimetry in the last study [35].

\section{Discussion}

Our table 1 highlights that the selected studies have not been conducted under the same conditions: study design, creams, irritants used and assessment methods. One must also take into account skin temperature, $\mathrm{pH}$, the thickness of the layer of cream, the number of applications, drying time before exposure, time required for application, time in contact with the irritant, concentrations and quantities of the irritant agents, areas of the body studied (back, hands or forearms), subjects studied (gender and ethnicity), presence or absence of occlusion and the length of the study $[4,28,41,53]$. Human skin is also characterized by an interindividual variability [22]. In the workplace, irritants are often a mixture of various substances, yet the trials selected in this study were carried out with isolated 
Table 4. Effects of vehicles compared to BCs

\begin{tabular}{|c|c|c|c|c|}
\hline Studies using vehicles & $\mathrm{BC}$ & Irritants & BC effect & Vehicle effect \\
\hline Nouaigui et al. [21], 1989 & Anthydro (silicone 5\%) & SLS 5\% & + & $=$ \\
\hline Elsner et al. [31], 1998 & PFPE (0.5-1-2-4\%) & $\begin{array}{l}\text { SLS 10\% } \\
\text { NaOH 0.5\% } \\
\text { LA 15\% } \\
\text { Toluene 99.5\% ] }\end{array}$ & + & $=$ \\
\hline Zhai et al. [35], 2000 & Protèque International & SLS $0.5 \%$ & + & $\begin{array}{l}\text { - (for scoring and evaporimetry }) \\
=(\text { for Doppler laser })\end{array}$ \\
\hline $\begin{array}{l}\text { Schliemann-Willers et al. } \\
\text { [38], } 2001\end{array}$ & PFPE (2-5\%) & $\begin{array}{l}\text { SLS 5\% } \\
\text { NaOH 0.5\% ] } \\
\text { LA 20\% } \\
\text { Toluene }\end{array}$ & $\begin{array}{l}+(\text { at } 5 \%) \\
+ \\
-\end{array}$ & $=$ \\
\hline
\end{tabular}

PFPE $=$ Perfluoroalkylpolyether $++=$ protective $($ or better for vehicle) effect; $-=$ no protective $($ or worst for vehicle) effect; $==$ no difference.

irritants. Duration of exposure, frequency of exposure and concentration of the irritant are 3 factors affecting occupational exposure. Because OCD is often the outcome of chronic exposure, the repetitive irritation test procedure could reproduce conditions closer to occupational exposure than studies with single contact. Concerning the application of BCs, an efficient layer and an efficient drying time are needed [18, 54]. It has also been shown in the study of Wigger-Alberti et al. [55] about self-application of a protection cream that certain areas of the hands were not sufficiently protected.

The range of quantities of cream applied found in our review is very wide. Schliemann et al. [56] pointed out that the quantities of BCs per skin surface area used in experiments might be far from those used in real conditions, leading to an overestimation of their efficacy.

While occupational skin diseases involve hands in more than $90 \%$ of cases [7], the most frequent application sites, in our selected studies, are the forearms and back. Overall, the studies have not taken into account friction movements which occur in realistic situations nor do they consider perspiration, resulting in an overestimation of the efficacy of BCs $[28,57]$.

Kütting et al. [58] published a prospective 4-armed randomized controlled trial on 1,020 metal workers regularly exposed to cutting fluids, followed during 12 months. The volunteers were assessed only by skin score. They showed that the skin protection programme (using BCs and skin care creams) is effective as well as the use of BCs alone, contrary to moisturizers alone, but the best protective effect was obtained by combining BCs and moisturizers. Kütting et al. [59] underline the contrast with the results of an Austrian prospective 4-armed randomized controlled trial on 485 of 1,006 workers coming from building $(\mathrm{n}=198)$ and timber $(\mathrm{n}=287)$ industries, followed over 1 year, in which each subject was assessed by clinical hand dermatitis categorization, transepidermal water loss and subjective perception. None of the 4 groups showed a protective effect on dermatitis. We must note that Kütting et al. assessed their subjects only by clinical scoring while, according to the recent paper of Sadhra et al. [52], it seems that clinical assessment is not sufficient without bioengineering. For the latter, it is also suggested that biophysical studies may provide information on changes in the skin condition before any visible dermatological changes occur [52] while other authors believe that clinical scoring is more appropriate at work $[36,60]$. According to several authors, the measure of transepidermal water loss is the best parameter of the barrier's alteration, even if some substances alter this parameter only slightly $[22,35,36,61,62]$.

There is a considerable lack of standardization in the selected studies, with more than 20 named commercial BCs tested in different ways against several different irritants (table 1), meaning that pooling of the results was not possible. The results were generally positive against 3 of the 4 more frequent irritants used (table 3). It seems that vehicles are as efficient as BCs (table 4). Our results 
stand in contrast with the Cochrane database conclusion. In their double-blind randomized controlled trial on 50 nurses comparing a BC and its vehicle, Berndt et al. [63] found an improvement in skin condition when using creams without any significant differences between the two groups, underlining however a lack of placebo-controlled, randomized clinical studies. Although the composition of BCs is sometimes very similar to that of simple emollients, we decided to differentiate between the two to focus only on studies investigating the BCs' efficiency. As explained in the Introduction, emollients are recommended after work. A larger comparison, including BCs and emollients, should be evaluated because they could be considered vehicles. We must note that the BCs cited in tables 2 and 4 are still available on the online market except for Protèque International.

By contrast to Wang et al. [64], some authors suggest that BCs should only be used for exposure to mild irritants (water, detergents, organic solvents or cutting oils) because they cannot neutralize a high dose of irritant [13, 61]. Indeed, after saturation, the agents sequestered in the layer of cream continue to penetrate the skin $[18,28]$ if the substances are not inactivated by BCs. This explains the potential of some BCs to induce contact dermatitis [4] and to increase the skin's susceptibility to irritants [61]. As may be seen in table 3, protection against toluene is very low and must be improved in the future. Only primary protection of as yet uncompromised skin can be of optimal efficacy in the prevention of OCD [63].

\section{Conclusion}

The comparability of trials evaluating the efficiency of BCs is affected by the lack of standardization even if a trend toward some degree of protection seems to be suggested, although vehicles appear to be just as efficient. The repetitive irritation test procedure is closer to the reality and could be used to assess exposures to one or more irritants.

However, the prevention of OCD goes beyond the pure application of BCs. Efforts should focus on field randomized controlled studies of skin protection programmes with standardized clinical and biophysical assessments.

\section{Acknowledgements}

The author wholeheartedly thanks Mrs. Nathalie Boonen and Dr. Valérie Libotte for their participation in the preparation of a previous version of this work.

\section{Disclosure Statement}

The authors have no conflicts of interest to disclose.

\section{References}

1 Kütting B, Weistenhöfer W, Baumeister T, Uter W, Drexler H: Current acceptance and implementation of preventive strategies for occupational hand eczema in 1,355 metalworkers in Germany. Br J Dermatol 2009;161: 390-396.

2 Saary J, Qureshi R, Palda V, DeKoven J, Pratt M, Skotnicki-Grant S, Holness L: A systematic review of contact dermatitis treatment and prevention. J Am Acad Dermatol 2005; 53:845-855.

-3 Belsito DV: Occupational contact dermatitis: etiology, prevalence, and resultant impairment/disability. J Am Acad Dermatol 2005; 53:303-313.

-4 Alvarez MA, Brown LH, Brancaccio RR: Are barrier creams actually effective? Curr Allergy Asthma Rep 2001;1:337-341.

5 Behroozy A, Keegel TG: Wet-work exposure: a main risk factor for occupational hand dermatitis. Saf Health Work 2014;5:175-180.
6 Teichmann A, Jacobi U, Waibler E, Sterry W, Lademann J: An in vivo model to evaluate the efficacy of barrier creams on the level of skin penetration of chemicals. Contact Dermatitis 2006;54:5-13.

7 Del Rosso JQ: Incorporation of a barrier protection cream in the management of chronic hand dermatitis: focus on data supporting an established hand protectant formulation and modifications designed to assist in barrier repair. J Clin Aesthet Dermatol 2014;7:40-48.

-8 Zhai H, Maibach HI: Barrier creams - skin protectants: can you protect skin? J Cosmet Dermatol 2002;1:20-23.

-9 Zur Mühlen A, Klotz A, Allef P, Weimans S, Veeger M, Thörner B, Eichler JO: Using skin models to assess the effects of a pre-work cream. Methodological aspects and perspective of the industry. Curr Probl Dermatol 2007;34:19-32.
10 Corazza M, Minghetti S, Bianchi A, Virgili A, Borghi A: Barrier creams: facts and controversies. Dermatitis 2014;25:327-333.

11 Mahmoud G, Lachapelle JM, Van Neste D: Histological assessment of skin damage by irritants: its possible use in the evaluation of a 'barrier cream'. Contact Dermatitis 1984;11: 179-185.

12 Zhai H, Maibach HI: Protection from irritants. Curr Probl Dermatol 2007;34:47-57.

$\checkmark 13$ Kresken J, Klotz A: Occupational skin-protection products - a review. Int Arch Occup Environ Health 2003;76:355-358.

14 Bauer A, Schmitt J, Bennett C, Coenraads PJ, Elsner P, English J, Williams HC: Interventions for preventing occupational irritant hand dermatitis. Cochrane Database Syst Rev 2010;6:CD004414.

15 Guillemin M, Murset JC, Lob M, Riquez J: Simple method to determine the efficiency of cream used for skin protection against solvent. $\mathrm{Br} J$ Ind Med 1974;31:310-316. 
16 Lauwerys RR, Dath T, Lachapelle JM, Buchet JP, Roels H: The influence of two barrier creams on the percutaneous absorption of $m$ xylene in man. J Occup Med 1978;20:17-20.

-17 Fischer T, Rystedt I: Skin protection against ionized cobalt and sodium lauryl sulphate with barrier creams. Contact Dermatitis 1983; 9:125-130.

18 Lodén M: The effect of 4 barrier creams on the absorption of water, benzene, and formaldehyde into excised human skin. Contact Dermatitis 1986;14:292-296.

$>19$ Blanken R, Nater JP, Veenhoff E: Protective effect of barrier creams and spray coatings against epoxy resins. Contact Dermatitis 1987;16:79-83.

20 Marks R, Dykes PJ, Hamami I: Two novel techniques for the evaluation of barrier creams. Br J Dermatol 1989;120:655-660.

-21 Nouaigui H, Antoine JL, Masmoudi ML, Van Neste DJ, Lachapelle JM: Études invasives et non invasives du pouvoir protecteur d'une crème siliconée et de son excipient vis-à-vis de l'irritation cutanée induite par le laurylsulfate de sodium. Ann Dermatol Vénéréol 1989; 116:389-398.

22 Frosch PJ, Kurte A, Pilz B: Efficacy of skin barrier creams. III. The repetitive irritation test (RIT) in humans. Contact Dermatitis 1993;29:113-118.

23 Frosch PJ, Kurte A: Efficacy of skin barrier creams. IV. The repetitive irritation test (RIT) with a set of 4 standard irritants. Contact Der matitis 1994;31:161-168.

-24 Treffel P, Gabard B, Juch R: Evaluation of barrier creams: an in vitro technique on human skin. Acta Derm Venereol 1994;74:7-11.

-25 Marks JG Jr, Fowler JF Jr, Sheretz EF, Rietschel RL: Prevention of poison ivy and poison oak allergic contact dermatitis by quaternium-18 bentonite. J Am Acad Dermatol 1995; 33:212-216.

26 Schlüter-Wigger W, Elsner P: Efficacy of 4 commercially available protective creams in the repetitive irritation test (RIT). Contact Dermatitis 1996;34:278-283.

-27 Zhai H, Maibach HI: Effect of barrier creams: human skin in vivo. Contact Dermatitis 1996; 35:92-96.

-28 De Fine Olivarius F, Brinch Hansen A, Karlsmark T, Wulf HC: Water protective effect of barrier creams and moisturizing creams: a new in vivo test method. Contact Dermatitis 1996;35:219-225.

-29 Baur X, Chen Z, Allmers H, Raulf-Heimsoth M: Results of wearing test with two different latex gloves with and without the use of skinprotection cream. Allergy 1998;53:441-444.

-30 Fartasch M, Schnetz E, Diepgen TL: Characterization of detergent-induced barrier alterations - effect of barrier cream on irritation. J Investig Dermatol Symp Proc 1998;3:121127.

-31 Elsner P, Wigger-Alberti W, Pantini G: Perfluoropolyethers in the prevention of irritant contact dermatitis. Dermatology 1998;197: 141-145.
32 Wigger-Alberti W, Rougier A, Richard A, Elsner P: Efficacy of protective creams in a modified repeated irritation test. Methodological aspects. Acta Derm Venereol 1998; 78:270-273.

33 Zhai H, Willard P, Maibach HI: Evaluating skin-protective materials against contact irritants and allergens. An in vivo screening human model. Contact Dermatitis 1998;38:155158.

34 Patterson SE, Williams JV, Marks JG Jr: Prevention of sodium lauryl sulfate irritant contact dermatitis by Pro-Q aerosol foam skin protectant. J Am Acad Dermatol 1999;40: 783-785.

35 Zhai H, Brachman F, Pelosi A, Anigbogu A, Ramos MB, Torralba MC, Maibach HI: A bioengineering study on the efficacy of a protectant lotion in preventing SLS-induced dermatitis. Skin Res Technol 2000;6:77-80.

36 Schnetz E, Diepgen TL, Elsner P, Frosch PJ, Klotz AJ, Kresken J, Kuss O, Merk H, Schwanitz HJ, Wigger-Alberti W, Fartasch M: Multicentre study for the development of an in vivo model to evaluate the influence of topical formulations on irritation. Contact Dermatitis. 2000;42:336-343.

37 Sun Q, Tran M, Smith B, Winefordner D: Insitu evaluation of a barrier-cream performance on human skin using laser-induced breakdown spectroscopy. Contact Dermatitis 2000;43:259-263.

38 Schliemann-Willers S, Wigger-Alberti W, Elsner P: Efficacy of a new class of perfluoropolyethers in the prevention of irritant contact dermatitis. Acta Derm Venereol 2001;81: 392-394.

39 Wöhrl S, Kriechbaumer N, Hemmer W, Focke M, Brannath W, Götz M, Jarisch R: A cream containing the chelator DTPA (diethylenetriaminepenta-acetic acid) can prevent contact allergic reactions to metals. Contact Dermatitis 2001;44:224-228.

40 Chilcott RP, Jenner J, Hotchkiss SAM, Rice P: Evaluation of barrier creams against sulphur mustard. I. In vitro studies using human skin. Skin Parmacol Appl Physiol 2002;15:225235.

41 Van der Bijl P, Gareis A, Lee H, van Eyck AD, Stander IA, Cilliers J: Effects of two barrier creams on the diffusion of benzo[a]pyrene across human skin. S Afr Dent J 2002;57:4952.

42 Wigger-Alberti W, Spoo J, Schliemann-Willers S, Klotz A, Elsner P: The tandem repeated irritation test: a new method to assess prevention of irritant combination damage to the skin. Acta Derm Venereol 2002;82:94-97.

43 Lati E, Gasser P, Lefeuvre L, Matta AM, Goug erot A: Study of the protective effects of a barrier cream preventing skin penetration of nickel nitrate. Nouv Dermatol 2004;23:208213.
4 Elsner P: Protection from combination exposure. Curr Probl Dermatol 2007;34:111-119.

45 Rieger T, Teichmann A, Richter H, Schanzer S, Sterry W, Lademann J: Evaluation of barrier creams - introduction and comparison of 3 in vivo methods. Contact Dermatitis 2007; 56:347-354.

46 Korinth G, Lüersen L, Schaller KH, Angerer J, Drexler H: Enhancement of percutaneous penetration of aniline and $o$-toluidine in vitro using skin barrier creams. Toxicol In Vitro 2008;22:812-818.

47 Slade HB, Fowler J, Draelos ZD, Reece BT, Cargill DI: Clinical efficacy evaluation of a novel barrier protection cream. Cutis 2008; 82:21-28.

48 Lembo S, Lembo C, Lo Conte V, Gallo L, La Bella S, Martellotta D, Ayala F: In vivo evaluation of a Poly-2p barrier cream protective effect. G Ital Dermatol Venereol 2010;145:703708 .

49 Roure R, Lanctin M, Nollent V, Bertin C: Methods to assess the protective efficacy of emollients against climatic and chemical aggressors. Dermatol Res Pract 2012;2012: 864734.

50 Schliemann S, Kleesz P, Elsner P: Protective creams fail to prevent solvent-induced cumulative skin irritation - results of a randomized double-blind study. Contact Dermatitis 2013; 69:363-371.

51 Schliemann S, Petri M, Elsner P: Preventing irritant contact dermatitis with protective creams: influence of the application dose. Contact Dermatitis 2014;70:19-26.

52 Sadhra SS, Kurmi OP, Mohammed NI, Foulds IS: Protection afforded by controlled application of a barrier cream: a study in a workplace setting. Br J Dermatol 2014;171:813-818.

53 Chilcott RP, Dalton CH, Ashley Z, Allen CE, Bradley ST, Maidment MP, Jenner J, Brown RF, Gwyther RJ, Rice P: Evaluation of barrier creams against sulphur mustard. II. In vivo and in vitro studies using the domestic white pig. Cutan Ocul Toxicol 2007;26:235-247.

54 Boman A, Mellström G: Percutaneous absorption of 3 organic solvents in the guinea pig. III. Effect of barrier creams. Contact Dermatitis 1989;21:134-140.

55 Wigger-Alberti W, Maraffio B, Wernli M, Elsner P: Self-application of a protective cream. Pitfalls of occupational protection. Arch Dermatol 1997;133:861-864.

56 Schliemann S, Petri M, Elsner P: How much skin protection cream is actually applied in the workplace? Determination of dose per skin surface area in nurses. Contact Dermatitis 2012;67:229-233.

57 Duca PG, Pelfini G, Ferguglia G, Settimi L, Peverelli C, Sevosi I, Terzaghi G: Efficacia dell'uso di creme-barriera nel prevenire affezioni dermatologiche in lavoratori delle tintostamperie: risultati di una sperimentazione randomizzata. Med Lav 1994;85:231238 
58 Kütting B, Uter W, Baumeister T, Schaller B, Weistenhöfer W, Drexler H: Non-invasive bioengineering methods in an intervention study in 1,020 male metal workers: results and implications for occupational dermatology. Contact Dermatitis 2010;62:272-278.

-59 Kütting B, Baumeister T, Weistenhöfer W, Pfahlberg A, Uter W, Drexler H: Effectiveness of skin protection measures in prevention of occupational hand eczema: results of a prospective randomized controlled trial over a follow-up period of 1 year. $\mathrm{Br} \mathrm{J}$ Dermatol 2010;162:362-370.
60 Winker R, Salameh B, Stolkovich S, Nikl M, Barth A, Ponocny E, Drexler H, Tappeiner G: Effectiveness of skin protection creams in the prevention of occupational dermatitis: results of a randomized, controlled trial. Int Arch Occup Environ Health 2009;82:653-662.

61 De Paepe K, Hachem JP, Vanpee E, Goossens A, Germaux MA, Lachapelle JM, Lambert J, Matthieu L, Roseeuw D, Suys E, Van Hecke E, Rogiers V: Beneficial effects of a skin tolerance-tested moisturizing cream on the barrier function in experimentally elicited irritant and allergic contact dermatitis. Contact Dermatitis 2001;44:337-343.

- 62 Frosch PJ, Schulze-Dirks A, Hoffmann M, Axthelm I, Kurte A: Efficacy of skin barrier creams. I. The repetitive irritation test (RIT) in the guinea pig. Contact Dermatitis 1993;28: 94-100.
3 Berndt U, Wigger-Alberti W, Gabard B, Elsner P: Efficacy of a barrier cream and its vehicle as protective measures against occupational irritant contact dermatitis. Contact Dermatitis 2000;42:77-80.

64 Wang SM, Shih TS, Huang YS, Chueh MR, Chou JS, Chang HY: Evaluation of the effectiveness of personal protective equipment against occupational exposure to $\mathrm{N}, \mathrm{N}$-dimethylformamide. JHazard Mater 2006;B138: 518-525. 